Research Article

\title{
The Characteristics of Seismic Response on Hard Interlayer Sites
}

\author{
Jie Su, ${ }^{1}$ Zhenghua Zhou, ${ }^{1}$ You Zhou, ${ }^{2}$ Xiaojun Li $\mathbb{D}^{1,3}$ Qing Dong, ${ }^{1}$ Yafei Wang, \\ Yuping Li, ${ }^{1}$ and Liu Chen ${ }^{1}$ \\ ${ }^{1}$ College of Transportation Science \& Engineering, Nanjing Tech University, Nanjing 210009, China \\ ${ }^{2}$ Cores and Samples Center of Land \& Resources, China Geological Survey, Sanhe, Hebei 065201, China \\ ${ }^{3}$ College of Architecture and Civil Engineering, Beijing University of Technology, Beijing 100124, China
}

Correspondence should be addressed to Xiaojun Li; beerli@vip.sina.com

Received 13 November 2019; Revised 26 April 2020; Accepted 22 May 2020; Published 25 June 2020

Academic Editor: Zahid Hossain

Copyright ( $\odot 2020$ Jie Su et al. This is an open access article distributed under the Creative Commons Attribution License, which permits unrestricted use, distribution, and reproduction in any medium, provided the original work is properly cited.

Based on the engineering geological data of a nuclear power plant site, nine engineering geological profiles were created with hard interlayers of different thicknesses. The equivalent linearization method of seismic motion segment-input used for one-dimensional nonlinear seismic response analysis was applied to study the effect of the interlayer thickness on the peak acceleration and the acceleration response spectra of the site seismic response. The results showed that there was an obvious influence of hard interlayer thickness on site seismic responses. With the increase of hard interlayer thickness, the site nonlinear effect on seismic responses decreased. Under the same thickness of the hard interlayer, the nonlinear effect of the site was strengthened with the higher input peak acceleration. In addition, the short-period acceleration response spectrum was found to be significantly influenced by the hard interlayer and showed that the longer the period, the less influence of the hard interlayer on the acceleration response spectrum coordinates. Moreover, the influenced frequency band was wider with the increase in the thickness of hard interlayer.

\section{Introduction}

The influence of site conditions on earthquake damage has been recognized widely [1-5]. For example, the 1906 San Francisco earthquake caused markedly severe damage on soft soil foundations throughout the city $[6,7]$. During the 1975 Haicheng earthquake in China [1], the damage of brick chimneys in Yingkou city and Panjin district was equivalent to that of Haicheng County and Dashiqiao, while the damage of typical brick houses in Haicheng County and Dashiqiao was far more severe than that in Yingkou city and Panjin district; this difference was related to the thicker overburden layer in the former areas. During the 1976 Tangshan earthquake [1], the seismic damage of two areas in Tianjin was quite different. The survey results showed that the site of the area suffering lighter damage consisted of a soft intercalation of mucky clay at a depth of approximately $10 \mathrm{~m}$. In particular, the earthquake that occurred in Mexico on 19 September 1985 further demonstrated that site conditions have a significant impact on earthquake damage [8]. During this earthquake, Mexico City, which was $400 \mathrm{~km}$ away from the epicentre, suffered severe damage, far exceeding the damage that occurred in the area around the city. The analysis results showed that Mexico City is located in a deep and weak sedimentary basin, which caused the amplification of seismic motion and the lengthening of the duration of strong seismic motion. The destructive earthquakes that occurred in the last 2 decades [9], such as Nepal 2015, Chile 2010, Sichuan 2008, and Kocaeli 1999, proved that the influence of local site conditions on the earthquake damage is substantial when compared to travel path effects and the effects induced by the proximity of earthquake sources.

The damage of earthquake was found to be very selective of site conditions [10-14] which generally refer to local geological conditions, such as the near-surface soil layer, 
topography, and fracture zones. Existing studies [10, 15-18] have shown that the impact of site conditions on seismic damage is due to their significant ground motion amplification or deamplification effect. The influence of the nearsurface soil layer on seismic effects has attracted a lot of research due to its widespread impact and the large number of sites involved, and the research studies focused on the formation age $[6,7,19-21]$, genetic type [22-25], thickness variability [26-28], structure [29-34], and dynamic characteristics of overlying soil layers [35-39]. Although many studies on site effects have been performed at home and abroad and the results are remarkable, there are few studies of the influence of hard interlayers on the site seismic response. In this paper, the one-dimensional seismic response analysis of a nuclear power plant site underlying a hard interlayer was performed to discuss the influence of the hard interlayer thickness on the site seismic response, in order to provide a basis on which the ground motion parameters for seismic design of similar sites will be determined. The site of this research is one of several soft soil sites in China's industry-specific projects for the further understanding of the impact of hard interlayers on ground motions. Thus, we confirm that the research in this manuscript has a certain reference value for understanding the characteristics of ground motions at similar sites.

\section{Site Description and Input Ground Motions}

2.1. Site Description. The site involved is a typical site for nuclear power plant site selection on soft soil site in China. It was found that there is a thick hard interlayer under the soft layer. Because of the importance of the project, it is necessary to study the influence of the hard interlayer on the seismic response of the site. For the confidentiality requirements of the nuclear engineering site, the specific location information is not convenient to disclose. The data derived from our in-situ tests and laboratory tests of the site are given in Table 1 and Figure 1. The site consists of a soft layer of silty clay and silty sand from the surface to a depth of $44.3 \mathrm{~m}$, beneath which the hard interlayer composed of basalt and volcanic breccia continues to a depth of $198 \mathrm{~m}$. Beneath the thick hard interlayer, a soft layer shows up again and extends to over $337.5 \mathrm{~m}$ with the measured shear wave velocity reaching $730 \mathrm{~m} / \mathrm{s}$ at a depth of $337.5 \mathrm{~m}$. According to the code for evaluation of seismic safety for engineering sites of China [40], the surface of the bedrock determined by drilling or the surface of the layer with the shear wave velocity not less than $700 \mathrm{~m} / \mathrm{s}$ should be used as the input interface of ground motion for class-I site when establishing the onedimensional site seismic response analysis model. Therefore, we chose the interface at the depth of $337.5 \mathrm{~m}$ as the interface of input ground motion, which is called the computational basis of the model.

It can be seen from Figure 1 that the shear wave velocity of the hard interlayers of the nuclear power plant site was about $1429 \mathrm{~m} / \mathrm{s}-2499 \mathrm{~m} / \mathrm{s}$, which was more than twice that of underlying silty clay and overlying silty sand. From qualitative analysis point of view, the hard interlayer has a high wave impedance ratio relative to the underlying and overlying soil layer, which will have a significant reflection effect on upward and downward ground motion, and the site amplification effect mainly depends on the overlying soil layer on the hard interlayer. In addition, the thick silty clay layer will show strong nonlinearity under the strong ground motion, and the thicker hard interlayer and soil layer will also have a significant impact on the lower-frequency ground motion.

2.2. Input Seismic Motion. The thick hard interlayer and soil layer of the analysis model will influence a wide frequency band of the site earthquake response, which means that not only the high-frequency seismic motion but also the lowfrequency (long-period) seismic motion will be influenced. Therefore, the input seismic motions with a relatively wider band were selected. Based on this, the east-west acceleration record obtained from a near-field strong motion station in Qingping, Mianzhu (approximately $3 \mathrm{~km}$ from the fault), during the Wenchuan Ms8.0 earthquake was selected as the seismic motion input [41], and its peak acceleration is 824.1 gal. The input acceleration time history and the corresponding acceleration response spectra are shown in Figure 2. From Figure 2, it can be seen that the input seismic motions have a wider frequency band, especially the abundant long-period components with a response spectrum of $25.6 \mathrm{gal}$ at the period of $20 \mathrm{~s}$. To consider the influence of the hard interlayer on the seismic response of soil layers under different input ground motions, the peak accelerations of the actual ground motions were scaled to $50 \mathrm{gal}, 100 \mathrm{gal}$, and $200 \mathrm{gal}$.

\section{Site Seismic Response Results}

One-dimensional analysis (i.e., assuming horizontal soil layers, boundaries of infinite lateral extension, and vertically propagating shear waves) has proved adequately to model the propagation of the seismic waves through the soil profile (e.g., [42, 43]). Then, the equivalent linear method for the one-dimensional site response analysis has been widely used in both research and engineering practices (e.g., $[9,17,36,42-44])$ due to its simplicity, flexibility, and robustness. Based on this method, many calculation programs are implemented and improved day by day, such as the SHAKE91 [45], ProShake [46], DEEPSOIL [47], and our LSSRLI-1 $[48,49]$ which has the same basic theory, and the validity of LSSRLI-1 was verified and compared with that of SHAKE91 and DEEPSOIL by Ma and Ding [50] Therefore, the one-dimensional seismic site response calculation of the nuclear power plant site underlying a hard interlayer in this paper will be carried out by our program LSSRLI-1. In view of the relevant literature available for the verification of procedure, this paper does not provide a detailed introduction.

3.1. One-Dimensional Site Seismic Response Analysis Model. As shown in Table 1, the soil profile consists of 17 major layers. For the application of the one-dimensional equivalent linear method, these major layers were further divided into 
TABLE 1: Information regarding soil strata collected from drilling results.

\begin{tabular}{|c|c|c|c|c|c|}
\hline No. & Depth $(\mathrm{m})$ & Soil property & Thickness (m) & Density $\left(\mathrm{t} / \mathrm{m}^{3}\right)$ & Category number \\
\hline 1 & 3.9 & Silty clay & 3.9 & 1.81 & 1 \\
\hline 2 & 13.4 & Silty sand & 9.5 & 1.93 & 2 \\
\hline 3 & 17 & Silty clay & 3.6 & 1.93 & 3 \\
\hline 4 & 21 & Silty clay & 4 & 1.89 & 4 \\
\hline 5 & 25.2 & Silty clay & 4.2 & 1.89 & 5 \\
\hline 6 & 32 & Silty clay & 6.8 & 1.89 & 4 \\
\hline 7 & 38 & Silty clay & 6 & 2.04 & 6 \\
\hline 8 & 42.7 & Silty clay & 4.7 & 1.96 & 7 \\
\hline 9 & 44.3 & Silty sand & 1.6 & 1.92 & 8 \\
\hline 10 & 92.9 & Basalt & 48.6 & 2.51 & 18 \\
\hline 11 & 198 & Volcanic breccia & 105.1 & 2.51 & 18 \\
\hline 12 & 204 & Silty clay & 6 & 2.06 & 9 \\
\hline 13 & 216 & Silty clay & 12 & 2.02 & 10 \\
\hline 14 & 279 & Silty clay & 63 & 2.07 & 11 \\
\hline 15 & 309.8 & Silty clay & 30.8 & 2.05 & 12 \\
\hline 16 & 311.1 & Silt sand & 1.3 & 2.06 & 13 \\
\hline 17 & 337.5 & Silty clay & 26.4 & 2.06 & 14 \\
\hline 18 & - & Silty clay & - & 2.55 & 19 \\
\hline
\end{tabular}

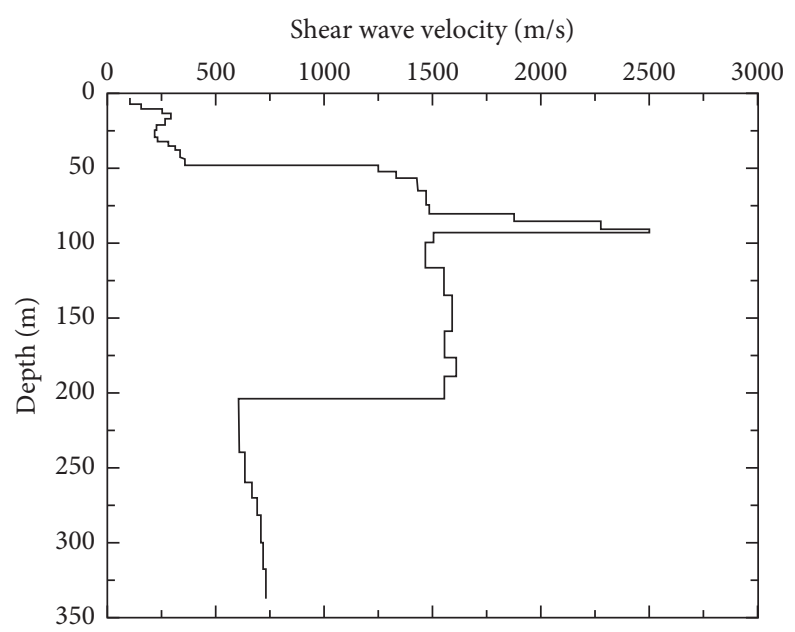

Figure 1: Shear wave velocity of the nuclear power plant site derived from the controlled borehole field test.

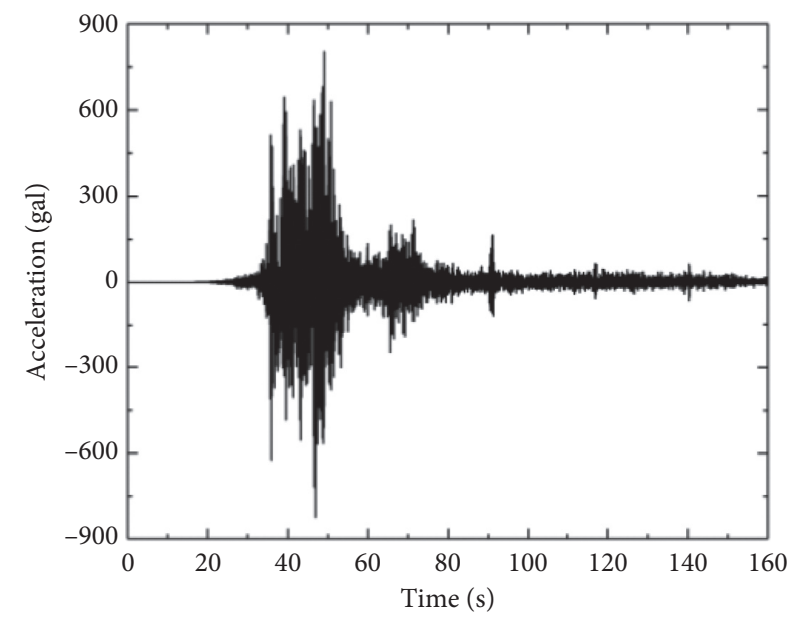

(a)

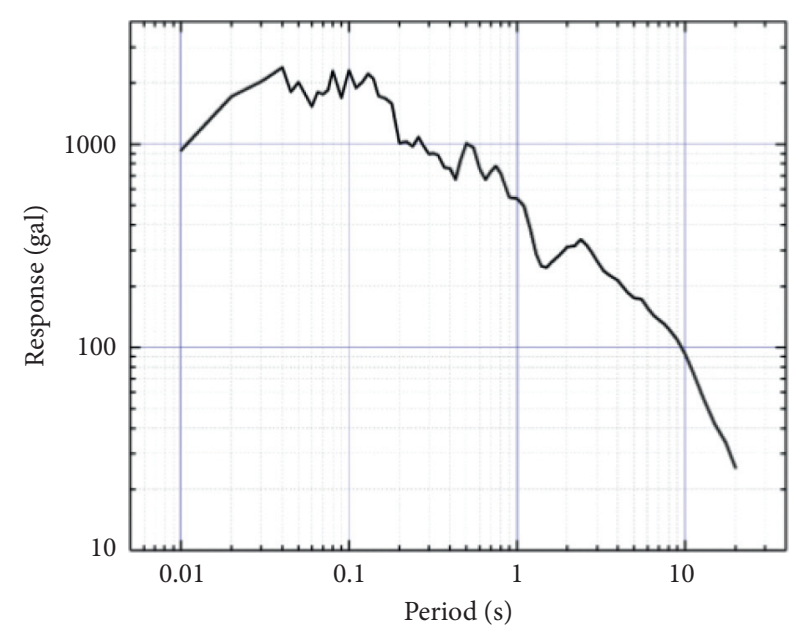

(b)

FIgURE 2: (a) Input acceleration history. (b) The response spectra of input acceleration. 
TABLE 2: Analysis models and the corresponding soil mechanical parameters.

\begin{tabular}{|c|c|c|c|c|c|c|}
\hline Sublayers & Soil property & Depth (m) & Thickness (m) & Shear wave velocity $(\mathrm{m} / \mathrm{s})$ & Density $\left(\mathrm{t} / \mathrm{m}^{3}\right)$ & Category number \\
\hline 1 & Silty clay & 3.9 & 3.9 & 105 & 1.81 & 1 \\
\hline 2 & \multirow{3}{*}{ Silty sand } & 7.0 & 3.1 & 156 & 1.93 & 2 \\
\hline 3 & & 10.0 & 3.0 & 254 & 1.93 & 2 \\
\hline 4 & & 13.4 & 3.4 & 289 & 1.93 & 2 \\
\hline 5 & \multirow{3}{*}{ Silty clay } & 17.0 & 3.6 & 264 & 1.93 & 3 \\
\hline 6 & & 21.0 & 4.0 & 224 & 1.89 & 4 \\
\hline 7 & & 25.2 & 4.2 & 218 & 1.89 & 5 \\
\hline 8 & \multirow{2}{*}{ Silty clay } & 29.0 & 3.8 & 229 & 1.89 & 4 \\
\hline 9 & & 32.0 & 3.0 & 277 & 1.89 & 4 \\
\hline 10 & \multirow{3}{*}{ Silty clay } & 35.0 & 3.0 & 312 & 2.04 & 6 \\
\hline 11 & & 38.0 & 3.0 & 333 & 2.04 & 6 \\
\hline 12 & & 42.7 & 4.7 & 347 & 1.96 & 7 \\
\hline 13 & Silty sand & 44.3 & 1.6 & 357 & 1.92 & 8 \\
\hline 14 & \multirow{3}{*}{ Basalt } & 48.0 & 3.7 & 1249 & 2.51 & 18 \\
\hline 15 & & 52.0 & 4.0 & 1332 & 2.51 & 18 \\
\hline 16 & & 56.0 & 4.0 & 1427 & 2.51 & 18 \\
\hline$\overline{17}$ & \multirow{2}{*}{ Basalt (silty clay) } & 60.0 & 4.0 & $1428(466)$ & $2.51(1.96)$ & $18(7)$ \\
\hline 18 & & 65.0 & 5.0 & $1470(470)$ & $2.51(1.96)$ & $18(7)$ \\
\hline 19 & \multirow{3}{*}{ Basalt (silty clay) } & 70.0 & 5.0 & $1470(474)$ & $2.51(1.96)$ & $18(7)$ \\
\hline 20 & & 74.2 & 4.2 & $1481(477)$ & $2.51(1.96)$ & $18(7)$ \\
\hline 21 & & 80.0 & 5.8 & $1874(482)$ & $2.51(1.98)$ & $18(15)$ \\
\hline 22 & \multirow{3}{*}{ Basalt (silty clay) } & 85.0 & 5.0 & $2272(486)$ & $2.51(1.98)$ & $18(15)$ \\
\hline 23 & & 90.2 & 5.2 & $2499(491)$ & $2.51(1.98)$ & $18(15)$ \\
\hline 24 & & 92.9 & 2.7 & $1500(493)$ & $2.51(1.98)$ & $18(15)$ \\
\hline 25 & \multirow{2}{*}{ Volcanic breccia (silty clay) } & 99.0 & 6.1 & $1463(498)$ & $2.51(1.98)$ & $18(15)$ \\
\hline 26 & & 105.0 & 6.0 & $1463(503)$ & $2.51(1.98)$ & $18(15)$ \\
\hline 27 & \multirow{3}{*}{ Volcanic breccia (silty clay) } & 111.0 & 6.0 & $1463(508)$ & $2.51(1.98)$ & $18(15)$ \\
\hline 28 & & 117.0 & 6.0 & $1552(513)$ & $2.51(1.98)$ & $18(15)$ \\
\hline 29 & & 123.0 & 6.0 & $1552(518)$ & $2.51(1.98)$ & $18(15)$ \\
\hline 30 & \multirow{4}{*}{ Volcanic breccia (silty clay) } & 129.0 & 6.0 & $1552(524)$ & $2.51(1.99)$ & $18(16)$ \\
\hline 31 & & 135.0 & 6.0 & $1588(529)$ & $2.51(1.99)$ & $18(16)$ \\
\hline 32 & & 141.0 & 6.0 & $1588(535)$ & $2.51(1.99)$ & $18(16)$ \\
\hline 33 & & 147.0 & 6.0 & $1588(540)$ & $2.51(1.99)$ & $18(16)$ \\
\hline 34 & \multirow{4}{*}{ Volcanic breccia (silty clay) } & 153.0 & 6.0 & $1588(546)$ & $2.51(1.99)$ & $18(16)$ \\
\hline 35 & & 159.0 & 6.0 & $1552(551)$ & $2.51(1.99)$ & $18(16)$ \\
\hline 36 & & 165.0 & 6.0 & $1552(557)$ & $2.51(1.99)$ & $18(17)$ \\
\hline 37 & & 171.0 & 6.0 & $1552(563)$ & $2.51(1.99)$ & $18(17)$ \\
\hline 38 & \multirow{5}{*}{ Volcanic breccia (silty clay) } & 177.0 & 6.0 & 1605 (569) & $2.51(1.99)$ & $18(17)$ \\
\hline 39 & & 183.0 & 6.0 & 1605 (574) & $2.51(1.99)$ & $18(17)$ \\
\hline 40 & & 189.0 & 6.0 & $1552(580)$ & $2.51(1.99)$ & 18 (17) \\
\hline 41 & & 195.0 & 6.0 & $1552(586)$ & $2.51(1.99)$ & $18(17)$ \\
\hline 42 & & 198.0 & 3.0 & $1552(589)$ & $2.51(1.99)$ & $18(17)$ \\
\hline 43 & \multirow{10}{*}{ Silty clay } & 204.0 & 6.0 & 601 & 2.06 & 9 \\
\hline 44 & & 210.0 & 6.0 & 603 & 2.02 & 10 \\
\hline 45 & & 216.0 & 6.0 & 605 & 2.02 & 10 \\
\hline 46 & & 222.0 & 6.0 & 608 & 2.07 & 11 \\
\hline 47 & & 228.0 & 6.0 & 608 & 2.07 & 11 \\
\hline 48 & & 234.0 & 6.0 & 608 & 2.07 & 11 \\
\hline 49 & & 240.0 & 6.0 & 635 & 2.07 & 11 \\
\hline 50 & & 246.0 & 6.0 & 635 & 2.07 & 11 \\
\hline 51 & & 252.0 & 6.0 & 635 & 2.07 & 11 \\
\hline 52 & & 260.0 & 8.0 & 667 & 2.07 & 11 \\
\hline
\end{tabular}


TABLE 2: Continued.

\begin{tabular}{|c|c|c|c|c|c|c|}
\hline Sublayers & Soil property & Depth $(\mathrm{m})$ & Thickness (m) & Shear wave velocity $(\mathrm{m} / \mathrm{s})$ & Density $\left(\mathrm{t} / \mathrm{m}^{3}\right)$ & Category number \\
\hline 53 & \multirow{16}{*}{ Silty clay } & 264.0 & 4.0 & 667 & 2.07 & 11 \\
\hline 54 & & 267.0 & 3.0 & 667 & 2.07 & 11 \\
\hline 55 & & 270.0 & 3.0 & 688 & 2.07 & 11 \\
\hline 56 & & 273.0 & 3.0 & 688 & 2.07 & 11 \\
\hline 57 & & 276.0 & 3.0 & 688 & 2.07 & 11 \\
\hline 58 & & 279.0 & 3.0 & 688 & 2.07 & 11 \\
\hline 59 & & 282.0 & 3.0 & 706 & 2.05 & 12 \\
\hline 60 & & 285.0 & 3.0 & 706 & 2.05 & 12 \\
\hline 61 & & 288.0 & 3.0 & 706 & 2.05 & 12 \\
\hline 62 & & 291.0 & 3.0 & 706 & 2.05 & 12 \\
\hline 63 & & 294.0 & 3.0 & 706 & 2.05 & 12 \\
\hline 64 & & 297.0 & 3.0 & 706 & 2.05 & 12 \\
\hline 65 & & 300.0 & 3.0 & 715 & 2.05 & 12 \\
\hline 66 & & 303.0 & 3.0 & 715 & 2.05 & 12 \\
\hline 67 & & 306.0 & 3.0 & 715 & 2.05 & 12 \\
\hline 68 & & 309.8 & 3.8 & 715 & 2.05 & 12 \\
\hline 69 & Silt sand & 311.1 & 1.3 & 715 & 2.06 & 13 \\
\hline 70 & \multirow{8}{*}{ Silty clay } & 315.0 & 3.9 & 715 & 2.06 & 14 \\
\hline 71 & & 318.0 & 3.0 & 730 & 2.06 & 14 \\
\hline 72 & & 321.0 & 3.0 & 730 & 2.06 & 14 \\
\hline 73 & & 324.0 & 3.0 & 730 & 2.06 & 14 \\
\hline 74 & & 327.0 & 3.0 & 730 & 2.06 & 14 \\
\hline 75 & & 330.0 & 3.0 & 730 & 2.06 & 14 \\
\hline 76 & & 333.0 & 3.0 & 730 & 2.06 & 14 \\
\hline 77 & & 337.5 & 4.5 & 730 & 2.06 & 14 \\
\hline 78 & tional basis of & & & 730 & 2.55 & 19 \\
\hline
\end{tabular}

TABLE 3: The dynamic nonlinear parameter of different soil categories.

\begin{tabular}{|c|c|c|c|c|c|c|c|c|c|c|}
\hline \multirow{2}{*}{$\begin{array}{l}\text { Category } \\
\text { number }\end{array}$} & \multirow{2}{*}{ Soil layer } & \multirow{2}{*}{$\begin{array}{l}\text { Modulus ratio or damping } \\
\text { ratio }\end{array}$} & \multicolumn{8}{|c|}{ Shear strain $\gamma\left(10^{-4}\right)$} \\
\hline & & & 0.05 & 0.1 & 0.5 & 1 & 5 & 10 & 50 & 100 \\
\hline \multirow[b]{2}{*}{1} & \multirow{2}{*}{ Silty clay } & $G / G_{\max }$ & 0.992 & 0.984 & 0.924 & 0.859 & 0.633 & 0.463 & 0.147 & 0.079 \\
\hline & & $\lambda$ & 0.019 & 0.030 & 0.046 & 0.058 & 0.092 & 0.112 & 0.169 & 0.184 \\
\hline \multirow{2}{*}{2} & \multirow{2}{*}{ Silt sand } & $G / G_{\max }$ & 0.992 & 0.984 & 0.925 & 0.861 & 0.664 & 0.497 & 0.165 & 0.090 \\
\hline & & $\lambda$ & 0.004 & 0.007 & 0.025 & 0.036 & 0.074 & 0.120 & 0.239 & 0.273 \\
\hline \multirow{2}{*}{3} & \multirow{2}{*}{ Silty clay } & $G / G_{\max }$ & 0.996 & 0.992 & 0.960 & 0.924 & 0.661 & 0.493 & 0.163 & 0.089 \\
\hline & & $\lambda$ & 0.005 & 0.009 & 0.032 & 0.047 & 0.065 & 0.103 & 0.192 & 0.215 \\
\hline \multirow{2}{*}{4} & \multirow{2}{*}{ Silty clay } & $G / G_{\max }$ & 0.993 & 0.987 & 0.937 & 0.881 & 0.718 & 0.560 & 0.203 & 0.113 \\
\hline & & $\lambda$ & 0.004 & 0.007 & 0.028 & 0.045 & 0.060 & 0.098 & 0.204 & 0.236 \\
\hline \multirow{2}{*}{5} & \multirow{2}{*}{ Silty clay } & $G / G_{\max }$ & 0.991 & 0.983 & 0.919 & 0.870 & 0.762 & 0.678 & 0.316 & 0.188 \\
\hline & & $\lambda$ & 0.005 & 0.009 & 0.032 & 0.047 & 0.055 & 0.091 & 0.193 & 0.224 \\
\hline \multirow{2}{*}{6} & \multirow{2}{*}{ Silty clay } & $G / G_{\max }$ & 0.994 & 0.989 & 0.946 & 0.897 & 0.728 & 0.572 & 0.211 & 0.118 \\
\hline & & $\lambda$ & 0.005 & 0.009 & 0.030 & 0.041 & 0.062 & 0.086 & 0.189 & 0.228 \\
\hline \multirow{2}{*}{7} & \multirow{2}{*}{ Silty clay } & $G / G_{\max }$ & 0.990 & 0.980 & 0.905 & 0.827 & 0.702 & 0.601 & 0.232 & 0.131 \\
\hline & & $\lambda$ & 0.005 & 0.009 & 0.032 & 0.047 & 0.061 & 0.099 & 0.198 & 0.226 \\
\hline \multirow{2}{*}{8} & \multirow{2}{*}{ Silt sand } & $G / G_{\max }$ & 0.989 & 0.978 & 0.947 & 0.906 & 0.822 & 0.716 & 0.371 & 0.227 \\
\hline & & $\lambda$ & 0.005 & 0.009 & 0.032 & 0.037 & 0.054 & 0.083 & 0.186 & 0.282 \\
\hline \multirow{2}{*}{9} & \multirow{2}{*}{ Silty clay } & $G / G_{\max }$ & 0.992 & 0.985 & 0.938 & 0.896 & 0.801 & 0.703 & 0.321 & 0.191 \\
\hline & & $\lambda$ & 0.005 & 0.009 & 0.032 & 0.044 & 0.063 & 0.085 & 0.172 & 0.208 \\
\hline \multirow{2}{*}{10} & \multirow{2}{*}{ Silty clay } & $G / G_{\max }$ & 0.993 & 0.986 & 0.943 & 0.905 & 0.834 & 0.763 & 0.439 & 0.281 \\
\hline & & $\lambda$ & 0.005 & 0.010 & 0.034 & 0.048 & 0.068 & 0.081 & 0.157 & 0.179 \\
\hline \multirow{2}{*}{11} & \multirow{2}{*}{ Silty clay } & $G / G_{\max }$ & 0.995 & 0.991 & 0.955 & 0.915 & 0.746 & 0.595 & 0.227 & 0.128 \\
\hline & & $\lambda$ & 0.002 & 0.004 & 0.018 & 0.031 & 0.056 & 0.094 & 0.203 & 0.238 \\
\hline \multirow[b]{2}{*}{12} & \multirow{2}{*}{ Silty clay } & $G / G_{\max }$ & 0.996 & 0.991 & 0.958 & 0.919 & 0.813 & 0.685 & 0.303 & 0.179 \\
\hline & & $\lambda$ & 0.002 & 0.004 & 0.018 & 0.030 & 0.050 & 0.083 & 0.180 & 0.211 \\
\hline
\end{tabular}


TABLE 3: Continued.

\begin{tabular}{|c|c|c|c|c|c|c|c|c|c|c|}
\hline \multirow{2}{*}{$\begin{array}{l}\text { Category } \\
\text { number }\end{array}$} & \multirow{2}{*}{ Soil layer } & \multirow{2}{*}{$\begin{array}{l}\text { Modulus ratio or damping } \\
\text { ratio }\end{array}$} & \multicolumn{8}{|c|}{ Shear strain $\gamma\left(10^{-4}\right)$} \\
\hline & & & 0.05 & 0.1 & 0.5 & 1 & 5 & 10 & 50 & 100 \\
\hline \multirow{2}{*}{13} & \multirow{2}{*}{ Silt sand } & $G / G_{\max }$ & 0.992 & 0.985 & 0.934 & 0.897 & 0.831 & 0.757 & 0.453 & 0.293 \\
\hline & & $\lambda$ & 0.001 & 0.003 & 0.012 & 0.018 & 0.035 & 0.050 & 0.104 & 0.120 \\
\hline \multirow{2}{*}{14} & \multirow{2}{*}{ Silty clay } & $G / G_{\max }$ & 0.989 & 0.978 & 0.913 & 0.876 & 0.782 & 0.701 & 0.413 & 0.262 \\
\hline & & $\lambda$ & 0.017 & 0.025 & 0.041 & 0.044 & 0.053 & 0.066 & 0.128 & 0.189 \\
\hline \multirow{2}{*}{15} & \multirow{2}{*}{ Silty clay } & $G / G_{\max }$ & 0.992 & 0.984 & 0.923 & 0.884 & 0.703 & 0.611 & 0.239 & 0.136 \\
\hline & & $\lambda$ & 0.005 & 0.009 & 0.032 & 0.047 & 0.071 & 0.088 & 0.175 & 0.206 \\
\hline \multirow{2}{*}{16} & \multirow{2}{*}{ Silty clay } & $G / G_{\max }$ & 0.993 & 0.986 & 0.935 & 0.886 & 0.713 & 0.624 & 0.249 & 0.142 \\
\hline & & $\lambda$ & 0.002 & 0.005 & 0.022 & 0.038 & 0.075 & 0.093 & 0.198 & 0.242 \\
\hline \multirow{2}{*}{17} & \multirow{2}{*}{ Silty clay } & $G / G_{\max }$ & 0.990 & 0.980 & 0.907 & 0.862 & 0.712 & 0.607 & 0.236 & 0.134 \\
\hline & & $\lambda$ & 0.021 & 0.032 & 0.061 & 0.078 & 0.118 & 0.143 & 0.179 & 0.198 \\
\hline \multirow{2}{*}{18} & \multirow{2}{*}{ Volcanic breccia } & $G / G_{\max }$ & 0.990 & 0.970 & 0.900 & 0.850 & 0.700 & 0.550 & 0.320 & 0.200 \\
\hline & & $\lambda$ & 0.004 & 0.006 & 0.019 & 0.030 & 0.075 & 0.090 & 0.110 & 0.120 \\
\hline \multirow{2}{*}{19} & Computational basis of the & $G / G_{\max }$ & 1.000 & 1.000 & 1.000 & 1.000 & 1.000 & 1.000 & 1.000 & 1.000 \\
\hline & model & $\lambda$ & 0.050 & 0.050 & 0.050 & 0.050 & 0.050 & 0.050 & 0.050 & 0.050 \\
\hline
\end{tabular}

TABLE 4: Information of the hard interlayer of analysis models.

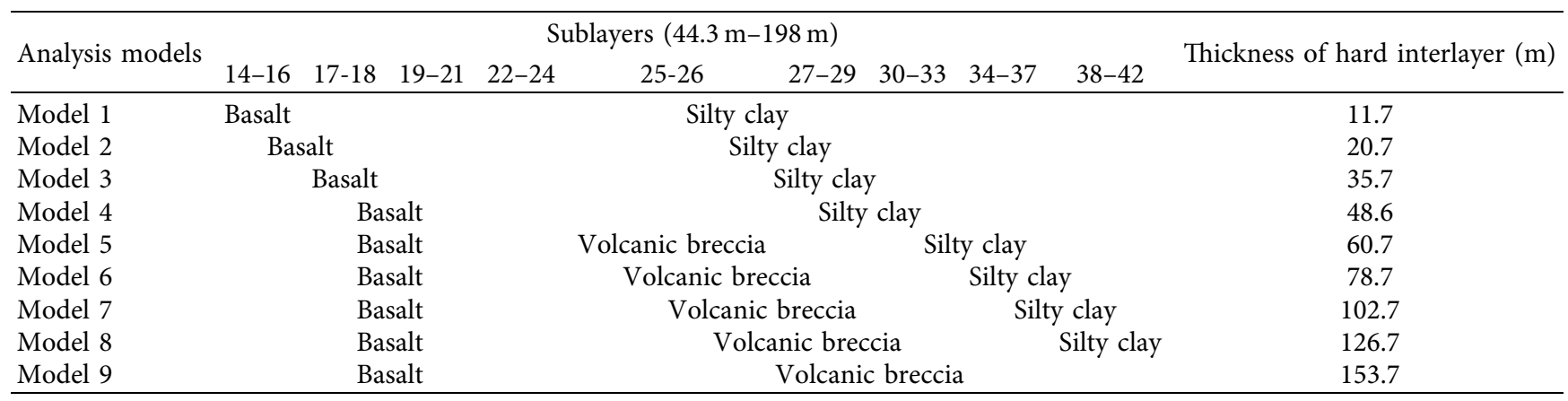

sublayers which were all assigned the same dynamic soil properties as the main layer. The thicknesses of the sublayers were chosen so that the site seismic response stability requirements of the time-domain method [51] in the LSSRLI-1 site seismic response calculation would be satisfied. Then, the one-dimensional analysis model for the equivalent linear method for site response analysis based on the partition of the major layers was established. Table 2 shows the composition of the one-dimensional analysis models, and the dynamic nonlinear parameter of different soil categories derived from the laboratory cyclic tests used in the analysis models is shown in Table 3.

For considering the influence of the hard interlayer on the site seismic response, the underlying silty clay (given in the brackets in Table 2) was used to replace the basalt and volcanic breccia to change the hard interlayer thickness so as to establish analytical models containing a hard interlayer of a different thickness, as shown in Table 4. The model 9 corresponded to the actual soil layer profile, while the thickness of the hard interlayer of model 8 is $126.7 \mathrm{~m}$ with the original volcanic breccia of layers 14 to 42 was replaced by silty clay. The mechanical parameters corresponding to the replacement silty clay are also given in the brackets in Tables 2 and 3, which were derived from the drilling data of the borehole nearby. The details of the remaining analysis

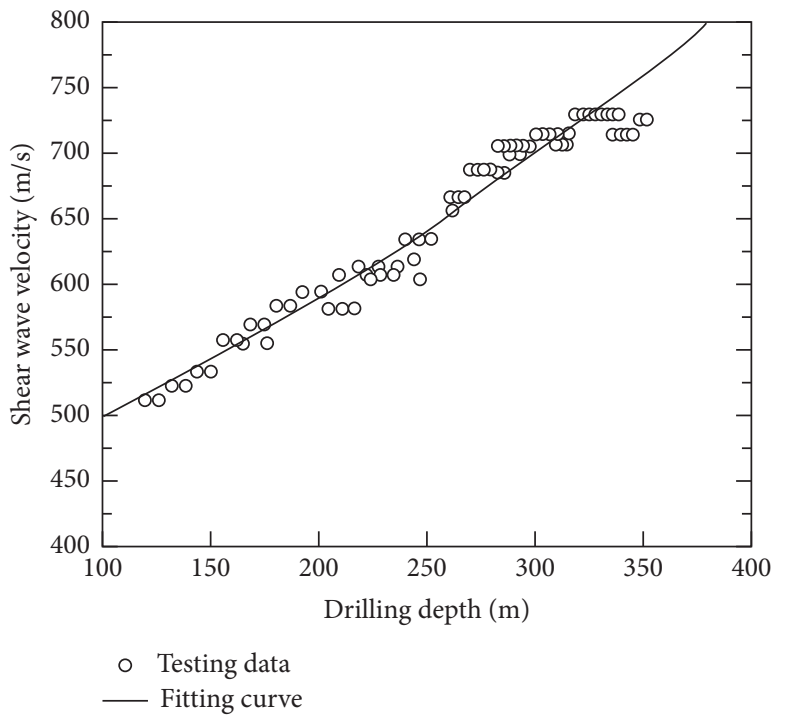

Figure 3: Sample points and regression curve.

models are provided in Table 4 . The shear wave velocities of the replacement silty clay layer were determined according to equation (1), which was based on the statistical regression of the in-situ test shear wave velocity data. The statistical data 
TABLE 5: The horizontal peak acceleration on the top of the hard interlayer and on the site surface under different input seismic motion levels.

\begin{tabular}{|c|c|c|c|c|c|c|}
\hline \multirow{2}{*}{ Models } & \multicolumn{2}{|c|}{$\begin{array}{l}50 \text { gal input peak } \\
\text { acceleration }\end{array}$} & \multicolumn{2}{|c|}{100 gal input peak acceleration } & \multicolumn{2}{|c|}{200 gal input peak acceleration } \\
\hline & $\begin{array}{l}\text { On the top of } \\
\text { hard interlayer }\end{array}$ & $\begin{array}{l}\text { On the site } \\
\text { surface }\end{array}$ & $\begin{array}{c}\text { On the top of hard } \\
\text { interlayer }\end{array}$ & On the site surface & On the top of hard interlayer & On the site surface \\
\hline Model 1 & 32.3 & 68.4 & 65.4 & 124.4 & 121.8 & 245.2 \\
\hline Model 2 & 32.4 & 64.3 & 64.8 & 122.8 & 116.5 & 235.0 \\
\hline Model 3 & 31.3 & 61.2 & 60.9 & 114.0 & 104.8 & 217.2 \\
\hline Model 4 & 29.5 & 61.3 & 57.0 & 106.7 & 96.0 & 206.5 \\
\hline Model 5 & 28.1 & 58.9 & 54.0 & 102.8 & 93.4 & 197.7 \\
\hline Model 6 & 25.3 & 58.9 & 48.0 & 116.5 & 90.0 & 199.9 \\
\hline Model 7 & 28.2 & 68.9 & 54.0 & 139.0 & 92.6 & 213.9 \\
\hline Model 8 & 26.1 & 80.3 & 46.8 & 150.2 & 98.1 & 250.8 \\
\hline Model 9 & 32.8 & 89.6 & 61.5 & 170.2 & 101.0 & 293.1 \\
\hline
\end{tabular}

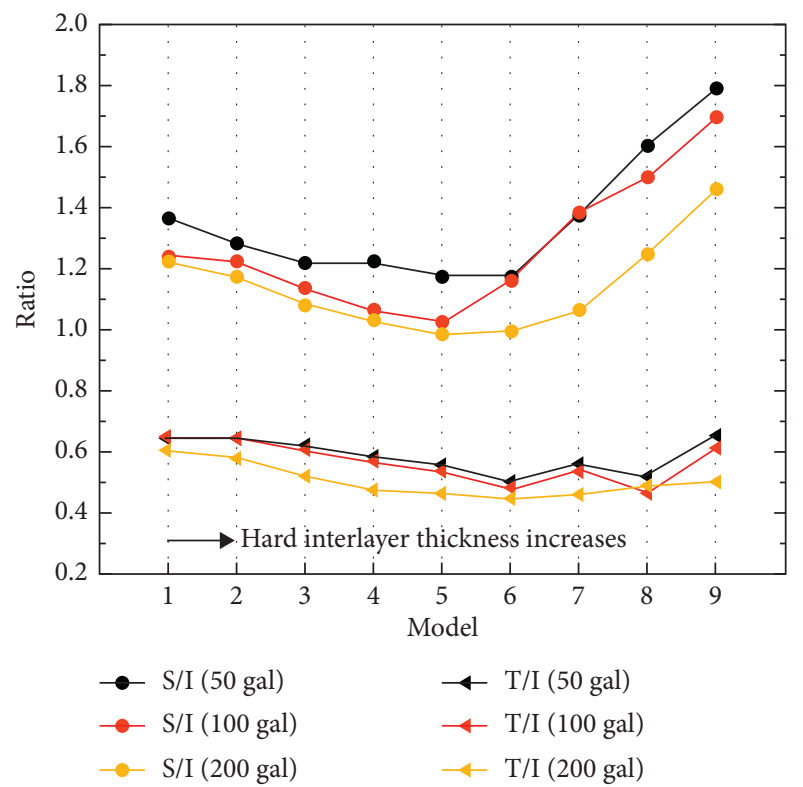

(a)

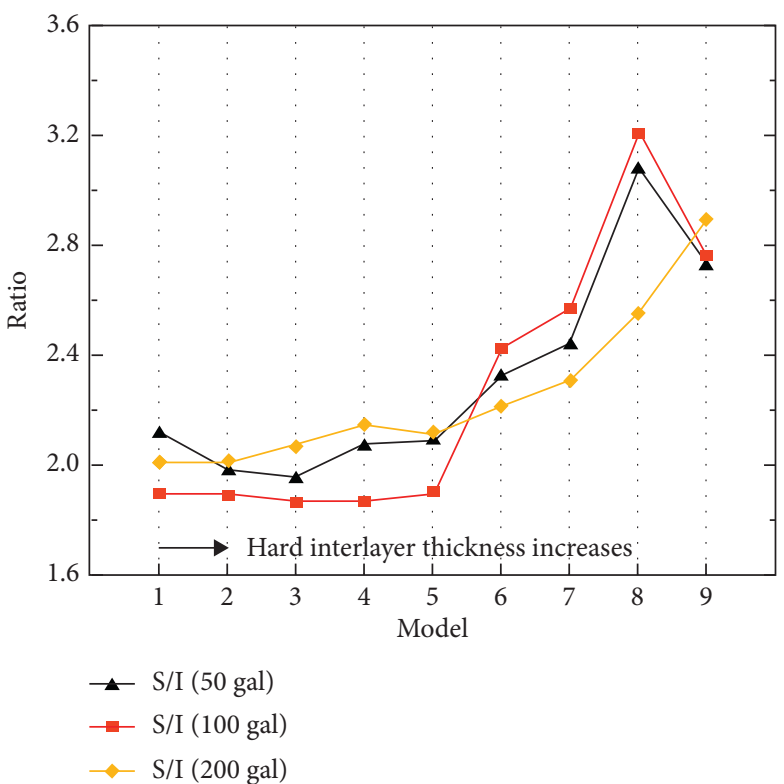

(b)

Figure 4: (a) Ratios of the peak accelerations on the site surface to those of the input seismic motions (S/I) and ratios of the peak accelerations on the top of the hard interlayer to those of the input seismic motions (T/I). (b) Ratios of the peak accelerations on the site surface to those on the top of the hard interlayer $(\mathrm{S} / \mathrm{T})$.

sampling point and the regression relationship are shown in Figure 3.

$$
V_{\mathrm{S}}=420.8 e^{0.0017 H}
$$

where $H$ represents the depth.

3.2. Site Response with Different Thicknesses of the Hard Interlayer. Table 5 lists the horizontal peak accelerations on the top of the hard interlayer and on the site surface, respectively. It can be seen that, under the same input seismic motions, the peak accelerations on the top of the hard interlayer were less than the input peak acceleration, while the peak accelerations on the site surface were greater than the input acceleration peak. From Table 1, a soft layer with a thickness of about $44.3 \mathrm{~m}$ was found to be between the hard interlayer and the site surface. These results indicate that the hard interlayer has obvious isolation effect on ground motion while the soft soil layer overlying the hard interlayer has a significant amplification effect on the seismic motion.

We further calculated the ratio between the input peak accelerations, the peak accelerations on the top of the hard interlayer, and the peak accelerations on the site surface of each model. The results (as shown in Figure 4) show that, under the same input seismic motion, the ratios of the peak accelerations on the top of the hard interlayer to the input peak accelerations (denoted as T/I) were smaller than 1.0 and the ratios of the peak accelerations on the site surface to the input peak accelerations (denoted as S/I) were greater than 1.0, which indicates that the overlying soil layers on the 


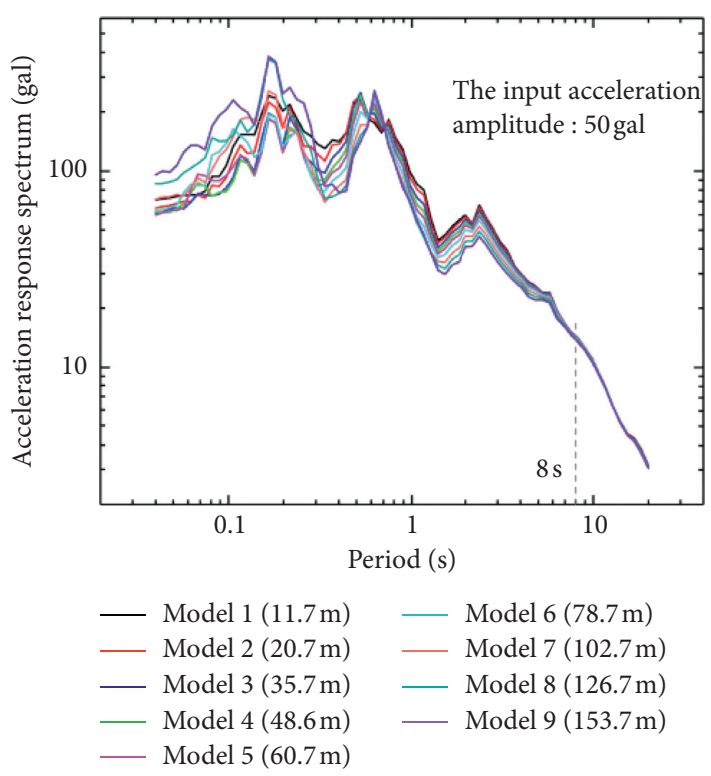

(a)
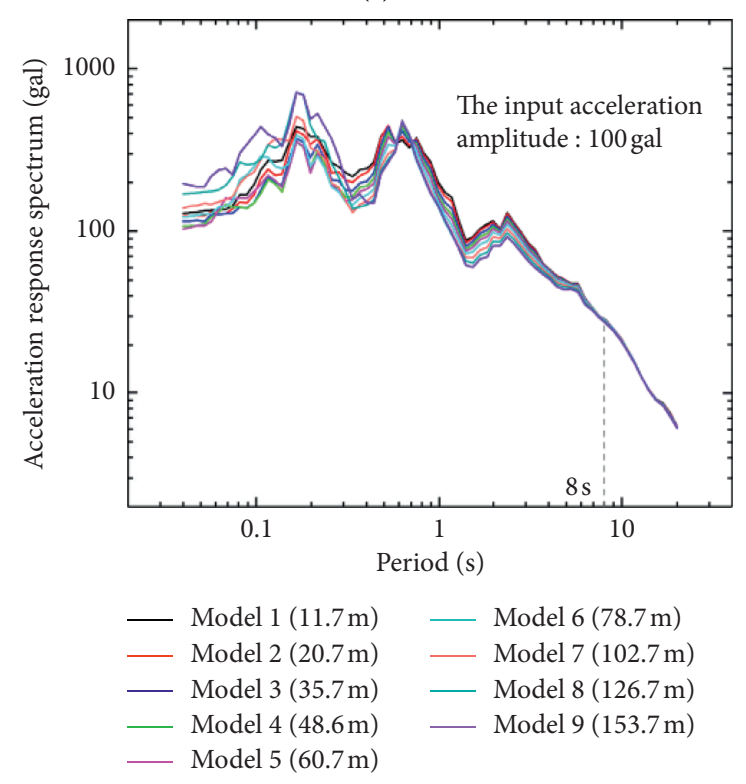

(c)

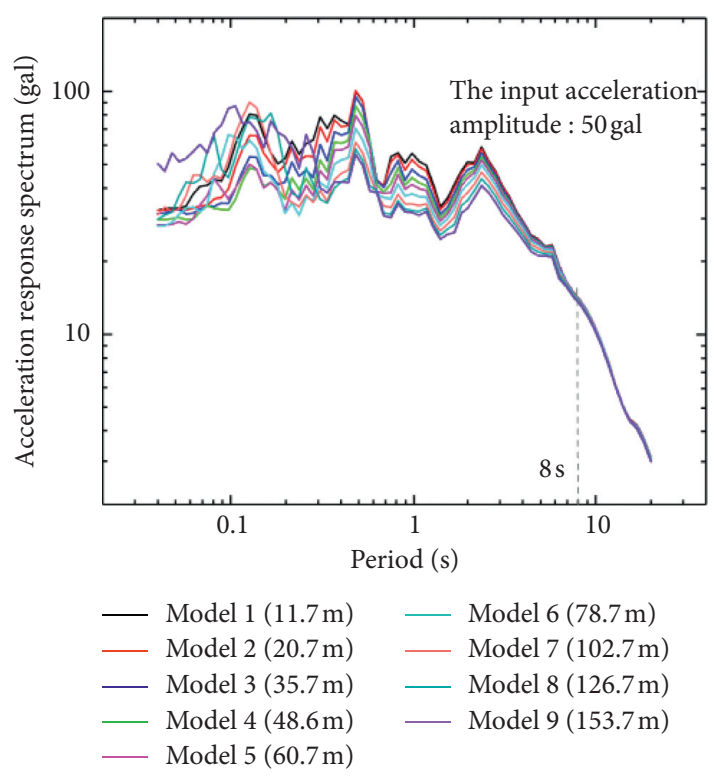

(b)

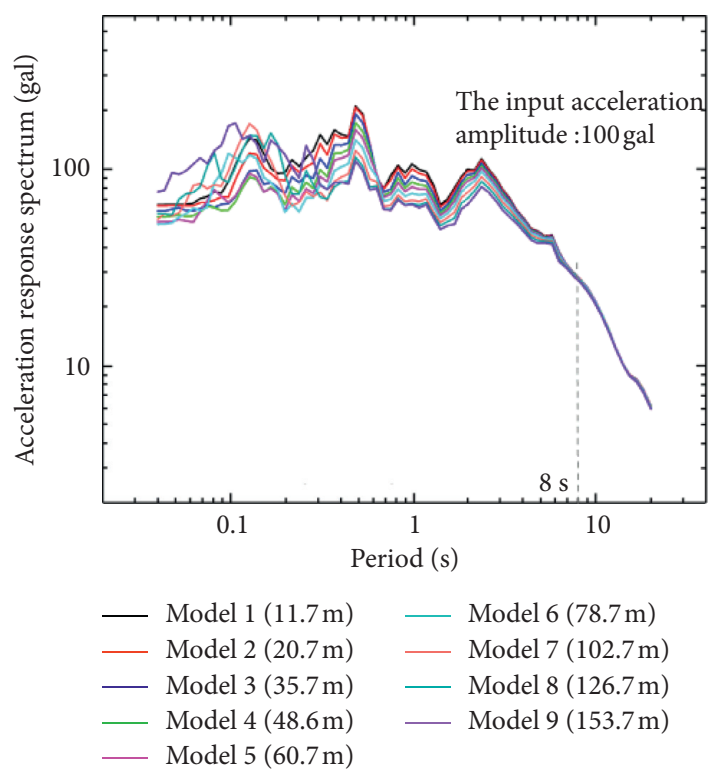

Figure 5: Continued. 

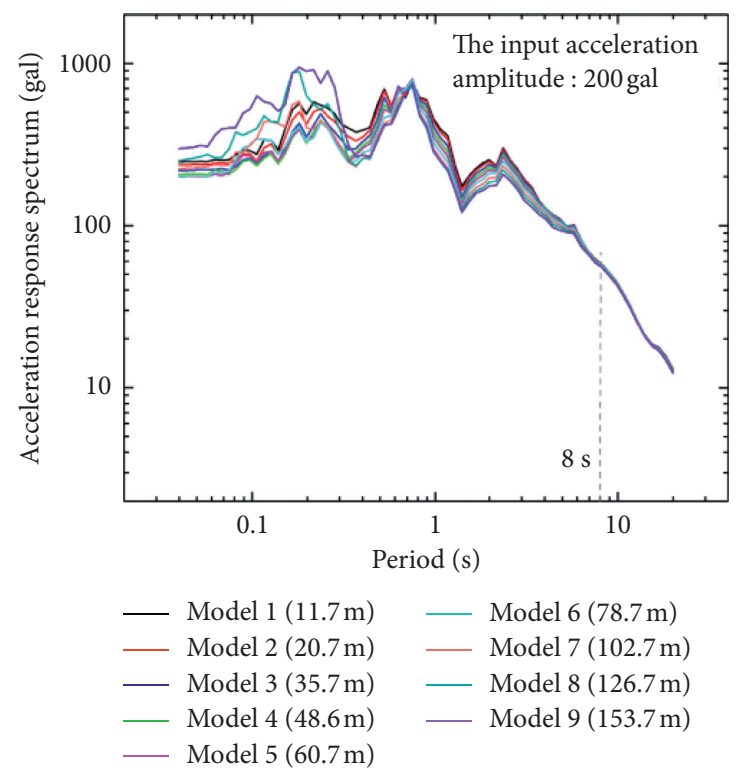

(e)
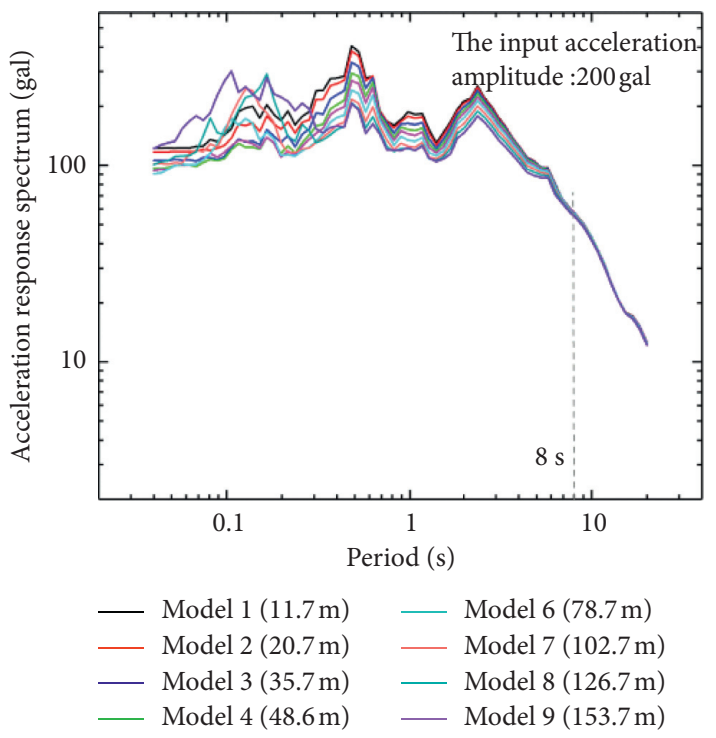

(f)

Figure 5: (a), (c), (e) The acceleration response spectrum coordinates on the site surface for different hard interlayer thicknesses. (b), (d), (f) The acceleration response spectrum coordinates on the top of the hard interlayer for different hard interlayer thicknesses.

hard interlayer has obvious amplification effect on ground motion. Besides, with the increasing of the thickness of the hard interlayer, there is a general tendency of S/I to get bigger, showing that the hard interlayer thickness also has an amplification influence on the peak acceleration of the site seismic response. Under the condition of the same hard interlayer thickness, both S/I of models (except models 6 and 7) and T/I of models (except model 8) decreased with the larger input acceleration, which means that the greater the input peak acceleration is, the stronger the nonlinear effect of the site.

As can be seen in Figure 4(b), under the same input seismic motion, the ratios of the peak accelerations on the site surface to those on the top of the hard interlayer (denoted as $\mathrm{S} / \mathrm{T}$ ) generally increased with the hard interlayer thickening, which indicated that the increase in the hard interlayer thickness reduced the nonlinear effect of the site and increased the site amplification effect on ground motion.

Figure 5 shows the acceleration response spectra on the top of the hard interlayer and on the site surface with different hard interlayer thicknesses under different input seismic motions. It can be seen that the acceleration response spectra for periods less than $8 \mathrm{~s}$ are significantly different, especially among the short periods. It indicates that the hard interlayer is more likely to affect the shortperiod acceleration response spectrum coordinates. Comparing the acceleration response spectrum coordinates under the same input seismic motion, both the acceleration response spectrum coordinates on the site surface and on the top of the hard interlayer showed a tendency to become higher with the increasing hard interlayer thickness. The acceleration response spectrum of $153.7 \mathrm{~m}$ hard interlayer thickness can be seen to be significantly higher than those with other hard interlayer thicknesses. This result shows that the thicker the hard interlayer is, the greater the influence on the short-period acceleration response spectrum coordinates.

\section{Conclusions}

Numerical studies were performed to investigate the influence of the hard interlayer on the site seismic response. Nine one-dimensional analysis models were established in accordance with the engineering geological data of a nuclear power plant site for the site response analyses utilizing the equivalent linear method. The numerical results are as follows:

(1) The peak accelerations on the top of the hard interlayer are less than the input peak accelerations, while the peak accelerations on the site surface are greater than the input peak accelerations under different input seismic motions and hard interlayer thicknesses.

(2) With the increase in the hard interlayer thickness, the S/T generally shows a gradual trend of increase, which indicated that the increase in the hard interlayer thickness reduced the nonlinear effect of the site.

(3) For the same hard interlayer thickness, S/I and T/I gradually decreased as the input peak acceleration increased. These characteristics mean that the higher the input peak acceleration is, the stronger the nonlinear effect of the site.

(4) The hard interlayer had an obvious influence on the short-period acceleration response spectrum coordinates. The affected frequency band can be wider with the increase in the hard interlayer thickness. 


\section{Data Availability}

The data used to support the findings of this study are available from the corresponding author upon request.

\section{Conflicts of Interest}

The authors declare that there are no conflicts of interest regarding the publication of this paper.

\section{Acknowledgments}

The authors gratefully acknowledge the support of the National Natural Science Foundation of China (Grant nos. U1839203 and 41374049).

\section{References}

[1] Y. X. Hu, P. S. Sun, Z. Y. Zhang, and Q. W. Tian, "Effects of site conditions on earthquake damage and ground motion," Earthquake Engineering and Engineering Vibration, vol. 1, pp. 35-41, 1980, in Chinese.

[2] F. J. Sanchez-Sesma, "Site effects on strong ground motion," Soil Dynamics and Earthquake Engineering, vol. 6, no. 2, pp. 124-132, 1987.

[3] J. S. Bo, X. L. Li, and S. Y. Li, "Some progress of study on the effect of site conditions on ground motion," World Earthquake Engineering, vol. 23, no. 2, pp. 11-15, 2003, in Chinese.

[4] D. M. Boore, "Can site response be predicted?" Journal of Earthquake Engineering, vol. 8, no. 1, pp. 1-41, 2004.

[5] A. Sextos, R. D. Risi, A. Pagliaroli et al., "Local site effects and incremental damage of buildings during the 2016 Central Italy earthquake sequence," Earthquake Spectra, vol. 34, no. 4, pp. 1639-1669, 2018.

[6] R. D. Borcherdt, "Effects of local geology on ground motion near San Francisco Bay," Bulletin of the Seismological Society of America, vol. 60, no. 1, pp. 29-61, 1970.

[7] R. D. Borcherdt and J. F. Gibbs, "Effect of local geological conditions in the San Francisco Bay region on ground motions and the intensities of the 1906 earthquake," Bulletin of the Seismological Society of America, vol. 66, no. 2, pp. 467500, 1976.

[8] H. B. Seed, M. P. Romo, J. I. Sun, A. Jaime, and J. Lysmer, "The Mexico earthquake of September 19, 1985-relationships between soil conditions and earthquake ground motions," Earthquake Spectra, vol. 4, no. 4, pp. 687-729, 1988.

[9] D. Stanko, S. Markušić, S. Strelec, and M. Gazdek, "Equivalent-linear site response analysis on the site of the historical Trakošćan castle, croatia using HVSR method," Environmental Earth Sciences, vol. 76, no. 18, pp. 1-21, 2017.

[10] R. B. Seed, S. E. Dickenson, and I. M. Idriss, "Principal geotechnical aspects of the 1989 loma prieta earthquake," Soils and Foundations, vol. 31, no. 1, pp. 1-26, 1991.

[11] S. Jeong, D. Asimaki, J. Dafni, and J. Wartman, "How topography-dependent are topographic effects? complementary numerical modeling of centrifuge experiments," Soil Dynamics and Earthquake Engineering, vol. 116, pp. 654-667, 2019.

[12] N. Zhang, Y. Gao, and R. Y. S. Pak, "Soil and topographic effects on ground motion of a surficially inhomogeneous semi-cylindrical canyon under oblique incident SH waves," Soil Dynamics and Earthquake Engineering, vol. 95, pp. 17-28, 2017.
[13] B. Pandey, R. S. Jakka, and A. Kumar, "Influence of local site conditions on strong ground motion characteristics at Tarai region of Uttarakhand, India," Natural Hazards, vol. 81, no. 2, pp. 1073-1089, 2016.

[14] O. A. Düzgün and A. Budak, "Effects of surface shapes and geotechnical conditions on the ground motion," KSCE Journal of Civil Engineering, vol. 19, no. 5, pp. 1336-1346, 2015.

[15] S. Jeong and B. A. Bradley, "Amplification of strong ground motions at heathcote valley during the 2010-2011 canterbury earthquakes: observation and 1D site response analysis," Soil Dynamics and Earthquake Engineering, vol. 100, pp. 345-356, 2017.

[16] S. Hailemikael, L. Lenti, S. Martino, A. Paciello, D. Rossi, and G. S. Mugnozza, "Ground-motion amplification at the Colle di Roio ridge, central Italy: a combined effect of stratigraphy and topography," Geophysical Journal International, vol. 206, no. 1, pp. 1-18, 2016.

[17] M. K. Akin, S. L. Kramer, and T. Topal, "Dynamic soil characterization and site response estimation for Erbaa, Tokat (Turkey)," Natural Hazards, vol. 82, no. 3, pp. 1833-1868, 2016.

[18] J. F. Semblat, M. Kham, E. Parara et al., "Seismic wave amplification: basin geometry vs soil layering," Soil Dynamics and Earthquake Engineering, vol. 25, no. 7-10, pp. 529-538, 2005.

[19] E. W. Woolery, Z. Wang, N. S. Carpenter, R. Street, and C. Brengman, "The central United States seismic observatory: site characterization, instrumentation, and recordings," Seismological Research Letters, vol. 87, no. 1, pp. 215-228, 2015.

[20] S. Hartzell, D. Carver, and R. A. Williams, "Site response, shallow shear-wave velocity, and damage in Los Gatos, California, from the 1989 loma prieta earthquake," Bulletin of the Seismological Society of America, vol. 91, no. 3, pp. 468478, 2001.

[21] H.-C. Huang, C.-S. Shieh, and H.-C. Chiu, "Linear and nonlinear behaviors of soft soil layers using Lotung downhole array in Taiwan," Terrestrial, Atmospheric and Oceanic Sciences, vol. 12, no. 3, pp. 503-524, 2001.

[22] A. Lessi-Cheimariou, I. J. Tromans, E. Rathje, and C. Robertson, "Sensitivity of surface hazard to different factors and site response analysis approaches: a case study for a soft rock site," Bulletin of Earthquake Engineering, vol. 17, no. 1, pp. 73-96, 2019.

[23] H. Li, J. B. Zhang, and J. C. Wu, "Effects of soft and hard interlayers on ground motion characteristics," China Earthquake Engineering Journal, vol. 36, no. 3, pp. 441-445, 2014, in Chinese.

[24] W. K. Hu and Q. J. Chen, "Response characteristic analysis of soil site with deep deposit under different bedrock seismic waves," Structural Engineers, vol. 26, no. 5, pp. 85-90, 2010, in Chinese.

[25] W. H. Li and C. G. Zhao, "Analysis of seismic dynamic response of layered alluvial valleys with soft interlayer," Rock and Soil Mechanics, vol. 30, no. 1, pp. 45-51, 2009, in Chinese.

[26] W. D. L. Finn and F. Ruz, "Amplification effects of thin softsurface layers," Earthquake Spectra, vol. 32, no. 4, pp. 21092126, 2016.

[27] M. Badaoui, M. K. Berrah, and A. Mebarki, "Soil height randomness influence on seismic response: case of an algiers site," Computers and Geotechnics, vol. 36, no. 1-2, pp. 102-112, 2009.

[28] G. X. Chen and J. H. Chen, "The effect of depth and thickness of soft soil layer on earthquake response for deep soft sites," 
World Earthquake Engineering, vol. 20, no. 3, pp. 66-73, 2004, in Chinese.

[29] N. Glinsky, E. Bertrand, and J. Régnier, "Numerical simulation of topographical and geological site effects. Applications to canonical topographies and rognes hill, south east France," Soil Dynamics and Earthquake Engineering, vol. 116, pp. 620-636, 2019.

[30] K. M. Yan, F. C. Liu, C. H. Zhu, Z. J. Wang, and J. J. Zhang, "Dynamic responses of slopes with intercalated soft layers under seismic excitations," Chinese Journal of Rock Mechanics and Engineering, vol. 36, no. 11, pp. 2686-2698, 2017, in Chinese.

[31] M. Massa, S. Barani, and S. Lovati, "Overview of topographic effects based on experimental observations: meaning, causes and possible interpretations," Geophysical Journal International, vol. 197, no. 3, pp. 1537-1550, 2014.

[32] G. Wang and K. Huang, "Effects of surface soil on ground motion characters," Earthquake Engineering and Engineering Vibration, vol. 33, no. 5, pp. 33-40, 2013, in Chinese.

[33] F. Gao, S. H. Yan, and X. C. Chen, "Analyses on seismic responses of ground," Chinese Journal of Rock Mechanics and Engineering, vol. 22, no. s2, pp. 2789-2793, 2003, in Chinese.

[34] J.-S. Bo, X.-L. Li, H.-S. Liu, Z.-Y. Wu, and D.-D. Liu, "Effects of soil layer construction on characteristic periods of response spectra," Earthquake Engineering and Engineering Vibration, vol. 23, no. 5, pp. 42-45, 2003, in Chinese.

[35] Q. Sun, X. Guo, and D. Dias, "Evaluation of the seismic site response in randomized velocity profiles using a statistical model with monte carlo simulations," Computers and Geotechnics, vol. 120, Article ID 103442, 2020.

[36] D.-K. Kim, H.-G. Park, and C.-G. Sun, "Design earthquake response spectrum affected by shallow soil deposit," Advances in Civil Engineering, vol. 2019, Article ID 4079217, 18 pages, 2019.

[37] B. Hassani, A. Yong, G. M. Atkinson, T. Feng, and L. Meng, "Comparison of site dominant frequency from earthquake and microseismic data in California," Bulletin of the Seismological Society of America, vol. 109, no. 3, pp. 1034-1040, 2019.

[38] G. A. Parker, J. A. Harmon, J. P. Stewart et al., "Proxy-based VS30 estimation in central and eastern North America," Bulletin of the Seismological Society of America, vol. 107, no. 1, pp. 117-131, 2017.

[39] W. Wang, Z.-H. Zhou, Y.-S. Wang, J.-S. Zhao, and X.-J. Li, "Response of typical sites under different earthquake motion input levels," Rock and Soil Mechanics, vol. 32, no. 4, pp. 1089-1094, 2011, in Chinese.

[40] GB17741-2005, Evaluation of Seismic Safety for Engineering Sites, China Standards Publishing, Beijing, China, 2005.

[41] Earthquake Disaster Prevention (China Seismological Bureau), Wenchuan 8.0 Earthquake Uncorrected Acceleration Records, Seismological Press, Beijing, China, 2008.

[42] I. M. Idriss and H. B. Seed, "Seismic response of horizontal soil layers," Journal of the Soil Mechanics and Foundations Division, vol. 94, no. 4, pp. 1003-1031, 1968.

[43] S. L. Kramer, Geotechnical Earthquake Engineering, Prentice Hall, Upper Saddle River, NJ, USA, 1996.

[44] W. Wang, Z. Zhou, Y. Wang, and J. Zhao, "Equivalent linear method of seismic motion segment-input," Journal of Basic Science and Engineering, vol. 18, pp. 130-137, 2010, in Chinese.

[45] I. M. Idriss and J. I. Sun, User's Manual for SHAKE91: A Computer Program for Conducting Equivalent Linear Seismic Response Analyses of Horizontally Layered Soil Deposits,
Center for Geotechnical Modelling, Department of Civil Engineering, University of California, Davis, CA, USA, 1992.

[46] Proshake, EduPro Civil Systems, Inc, Sammamish, WA, USA, 2013.

[47] Y. M. A. Hashash, Deep soil user manual and tutorial, 2020.

[48] X. J. Li and Z. P. Liao, "Visco-elasto-plastic model of soil stress-strain relationship," Earthquake Engineering and Engineering Vibration, vol. 9, no. 3, pp. 65-72, 1989, in Chinese.

[49] Z. P. Liao, Seismic Microzoning-Theory and Practice, Seismological Press, Beijing, China, 1990.

[50] J. L. Ma and H. P. Ding, "Comparison of general calculation programs for one-dimensional site seismic response based on equivalent linearization method," Technology for Earthquake Disaster Prevention, vol. 12, no. 4, pp. 725-742, 2017, in Chinese.

[51] Z. P. Liao, Introduction to Wave Motion Theories in Engineering, Science Press, Beijing, China, 1996. 